\title{
Analisis Performa Access Control List menggunakan Metode Firewall Policy Base
}

\section{Performance Analysis of the Access Control List Using the Firewall Policy- Based Method}

Firmansyah $^{1}$, Mochamad Wahyudi ${ }^{2}$

${ }^{1}$ Sekolah Tinggi Manajemen Informatika dan Komputer Nusa Mandiri, Indonesia

${ }^{2}$ Universitas Bina Sarana Informatika, Indonesia

\section{Article Info}

Article history:

Received, 7 Februari 2021

Revised, 17 April 2021

Accepted, 10 Mei 2021

\section{Kata Kunci:}

Jaringan Komputer

Cybercrime

Zone Based Policy

Firewall

Access Control List

Keywords:
Computer Network
Cybercrime
Zone Based Policy
Firewall
Access Control List

\begin{abstract}
ABSTRAK
Pemanfaatan teknologi informasi mampu mendukung mobilitas yang begitu cepat dan sangat efesien. Kini, hampir semua transfer data dilakukan menggunakan jaringan komputer dan bersifat terbuka. dengan terjadinya transfer data yang bersifat terbuka hal ini mampu memicu terjadinya kejahatan didalam dunia jaringan komputer (cybercrime). Penerapan keamanan jaringan komputer merupakan hal yang sangat vital. untuk memiminalisir cybercrime didalam jaringan komputer, maka diterapkanlah keamanan jaringan menggunakan metode zone-based policy firewall. Zone-based policy firewall mampu melakukan pembatasan akses berdasarkan mekanisme keamanan yang digunakan untuk melindungi sistem internal dari gangguan para pelaku Cybercrime atau pihak-pihak lain yang ingin memasuki kedalam sistem tanpa mempunyai hak akses. dari hasil penelitian analisa performa access control list menggunakan metode zon based policy firewall didapatkan penerapan keamanan jaringan komputer zonebased policy firewall mampu membatasi akses menuju server dari client yang terhubung didalam jaringan yang sama. Serta zone-based policy firewall mampu menyembunyikan hop count yang dilalui untuk menghubungkan antara client dengan server.
\end{abstract}

\section{ABSTRACT}

The use of information technology is able to support mobility that is so fast and very efficient. Today, almost all data transfers are done using computer networks and are open in nature. With the occurrence of open data transfer, it is able to trigger crime in the world of computer networks (cybercrime). The application of computer network security is very vital. To minimize cybercrime in computer networks, network security is implemented using a zone-based policy firewall method. Zone-based policy firewalls are able to restrict access based on security mechanisms used to protect internal systems from interference by cybercrime actors or other parties who want to enter the system without having access rights. From the research, the analysis of the performance of the access control list using the zone based policy firewall method, it was found that the application of zone-based policy firewall computer network security was able to limit access to the server from clients connected to the same network. The zone-based policy firewall is also able to hide the hop count that is passed to connect the client to the server.

This is an open access article under the CC BY-SAlicense.

\section{Penulis Korespondensi:}

Firmansyah,

Program Studi Sistem Informasi,

Sekolah Tinggi Manajemen Informatika dan Komputer Nusa Mandiri,

Email: firmansyah.fmy@ nusamandiri.ac.id 


\section{PENDAHULUAN}

Perkembangan teknologi jaringan komputer setiap harinya selalu mengalami peningkatan dan pembaharuan, hal ini dapat menyebabkan potensi terjadinya ancaman di dalam dunia internet [1]. Berdasarkan data yang didapatkan dari APJII (Asosiasi Penyelenggara Jasa Internet Indonesia) pengguna layanan internet di Indonesia pada tahun 2018 sebesar 171.176.716 dari 264.161.600 jiwa. Meskipun, jaringan inernet sudah menjadi platform utama di Indonesia dalam berbagai kegiatan, akan tetapi masalah keamanan dan privasi masih menjadi sebuah masalah yang seringkali muncul terutama dalam transaksi elektronik [2]. Semakin bertumbuhnya pengunalayanan internet di Indonesia akan berbanding lurus dengan kerentanan dari sebuah data. Hal ini akan berpotensi terjadinya kelemahan dari sistem keamanan data didalam jaringan internet. Kejahatan didalam dunia maya telah menjadi sebuah anacaman serius seiring pesatnya pertumbuhan internet di Indonesia [3]. Keamanan jaringan sangatlah vital bagi sebuah jaringan komputer, kelemahan-kelemahan yang terdapat pada jaringan komputer jika tidak dilindungi dan dijaga dengan baik akan menyebabkan sebuah kerugian [4] . Bahkan, sistem keamanan jaringan komputer beberapa tahun ini menjadi sebuah fokus utama dalam dunia jaringan komputer, hal ini disebabkan tingginya ancaman dan serangan dari internet.

Kejahatan didalam jaringan internet atau Cybercrime sulit untuk dideteksi, dikarenakan para pelaku memiliki banyak waktu untuk melarikan diri dari lokasi mereka dalam melakukan kejahatan tersebut [4]. Marak terjadinya kasus Cybercrime belakangan ini, menjadi sebuah kecemasan bagi pengguna layanan internet terutama bagi perusahaan yang memiliki data center yang dapat diakses melalui internet [5]. Sebuah keamanan jaringan komputer harus mempertimbangkan akses kenyamanan dan keamanan yang digunakan [6]. Manajemen firewall dapat memfasilitasi keamanan hanya untuk wilayah atau security policy tertentu saja yang akan dapat melakukan akses metode dasar adalah dengan menggunakan firewall tunggal yang menjadi penyangga jaringan internal dan external [7].

Pengimplementasian keamanan jaringan menggunakan metode zone-based policy firewall diharapkan mampu meminimalisir terjadinya kebocoran data. Zone-based police merupakan sebuah motode dari Access Control List (ACL) merupakan penyataan perizinan atau penolakan yang diterapkan pada sebuah alamat jaringan atau pada lapisan protokol dan ACL dapat digunakan untuk menentukan akses dari keluar masuknya sebuah paket didalam jaringan sedangkan frame relay merupakan teknologi yang menghandalkan frame-frame yang diteruskan untuk melakukan pengiriman paket data [8], dan dimana frame adalah sebuah paket data [9]. Zone-based policy firewall menggunakan mekanisme keamanan yang digunakan untuk melindungi sistem internal dari gangguan para pelaku Cybercrime atau pihak-pihak lain yang ingin memasuki kedalam sistem tanpa mempunyai hak akses. Teknik-teknik sistem keamanan jaringan dan pencegahan terhadap serangan pada sistem informasi perlu dikembangkan sehingga integrity, availability dan confidentiality [10][11]. Salah satunya adalah dengan cara membangun sistem keamanan jaringan dan sistem pencegahan serangan yaitu dengan pengimplementasian Zone-based policy firewall menyediakan keamanan berbasis zona yang memungkinkan kebijakan layanan berdasarkan zona yang sama walaupun berbeda interface pada router. Terdapat dua fitur yang harus diaktifkan untuk dapat berkomunikasi dengan zone-based policy firewall yaitu nama zona yang digunakan dan manajemen zona yang ditetapkan [12]. Interface pengguna memungkinkan pengguna layanan untuk mementukan zona dan kebijakan secara berbeda dari keamanan virtual. Serta, lalu lintas antar zona akan dibatasi oleh firewall sesuai dengan kebijakan access control policy [13].

Pada penelitian sebelumnya, implementasi teknik Demilitarized Zone (DMZ) pada layanan server jaringan Local Area Network (LAN) dapat melakukan filter terhadap serangan DoS jenis Internet Control Message Protocol (ICMP) flooding attack dan User Datagram Protocol (UDP) flooding attack [13]. Pada penelitian lainnya, terbentuknya koneksi antar jaringan dalam topologi beserta suksesnya fungsi dari firewall dan bekerjanya rule untuk area DMZ. Keberhasilan dalam pengaplikasian diuji kembali dengan melakukan beberapa metode serangan yang akan ditanggulangi oleh konfigurasi yang telah diterapkan pada alat jaringan beserta server [14]. Sedangkan pada penelitian lainnya pula, firewall DMZ bekerja untuk membuat semua paket yang akan masuk dan keluar jaringan harus melalui suricata, sehingga suricata akan memeriksa paket tersebut dan ketika ada paket yang termasuk dalam paket yang dicurigai oleh suricata, firewall mikrotik akan mengambil alih untuk melakukan tindakan pada paket tersebut [15]. Diharapkan dengan pengimplementasian Zone-based policy firewall mampu meminimalisir kejahatan didalam dunia jaringan komputer dikarenakan telah dilakukannya pembatasan hak akses berdasarkan zona-zona yang telah ditentunkan. Serta pengimplementasian Zone-based policy firewall mampu mempermudah didalam manajemen suatu keamanan jaringan.

\section{METODE PENELITIAN}

Dalam penelitian jaringan Zone-Base Policy Firewall peneliti menggunakan bantuan software Cisco Packet Tracer Version: 7.0.0.0305 untuk membuat simulasi jaringan komputer namun tidak mengurangi dan tidak merubah fitur seperti device aslinya. Untuk melakukan penelitian Zone-Base Policy Firewall peneliti menggunakan tiga (3) perangkat router series Cisco1941/K9 dengan Cisco IOS Software version 15.1(4) M4 serta mengaktifkan Security Technology Package yang dapat terlihat pada gambar 1. Untuk mengetahui performa dari pengimplementasian Zone-based policy firewall peneliti melakukan pengujian berdasarkan sebelum dan setelah pengimplementasian Zone-based policy firewall dengan melakukan pengiriman paket data dari zona yang berbeda. 


$\begin{array}{llll}\text { Technology Package License Information for Module:'c1900' } & & \\ & & & \\ \text { Technology } & \text { Technology-package } & \text { Technology-package } \\ & \text { Current } & \text { TYpe } & \text { Next reboot } \\ \text { ipbase } & \text { ipbasek9 } & \text { Permanent } & \text { ipbasek9 } \\ \text { security } & \text { securityk9 } & \text { Evaluation } & \text { securityk9 } \\ \text { data } & \text { disable } & \text { None } & \text { None }\end{array}$

Gambar 1. Technology-package securityk9

Metode penelitian yang digunakan dalam penelitian ini menggunakan The Security Policy Development Life Cycle (SPDLC), yang memiliki enam (6) tahapan, yaitu:

1. Identifikasi

Identifikasi digunakan untuk melakukan pengidentifikasian terhadap permasalahan keamanan didalam jaringan komputer.

2. Analisis

Pada tahapan ini penulis melakukan percobaan untuk mengetahui resiko dan ancaman didalam keamanan jaringan sebelum dan sesudah pengimplementasian Firewall Base Policy.

3. Perancangan

Tahapan ini penulis melakukan perancangan keamanan jaringan Firewall Base Policy.

4. Implementasi

Pada tahapan ini penulis melakukan konfigurasi Firewall Base Policy dan melakukan tahapan uji konektifitas terhadap keamanan jaringan.

5. Audit

Tahap audit digunakan untuk melakukan pemeriksaan terhadap system keamanan yang telah diimplementasikan.

6. Evaluasi

Tahapan evaluasi digunakan untuk melakukan evalusi system keamanan yang telah diterapkan.

\section{HASIL DAN ANALISIS}

Terlihat pada gambar 2 skema jaringan yang digunakan dalam pengimplementasikan jaringan berbasis Zone-Base Policy Firewall. Terdapat 1 (Satu) perangkat server yang terkoneksi dengan jaringan lokal R1. Pengimplementasian Zone-Base Policy Firewall akan memberikan batasan akses dan limitasi menuju server berdasarkan kesamaan zona. Hak akses menuju server hanya dapat dilakukan oleh jaringan yang berada pada R3 dengan menggunakan network 192.168.3.0/24 dan tidak diizinkan untuk melakukan akses menuju server untuk network 192.168.2.0/24. Namun, network 192.168.2.0/24 dengan network 192.168.3.0/24 tetap dapat saling berkomunikasi satu dengan lainnya.

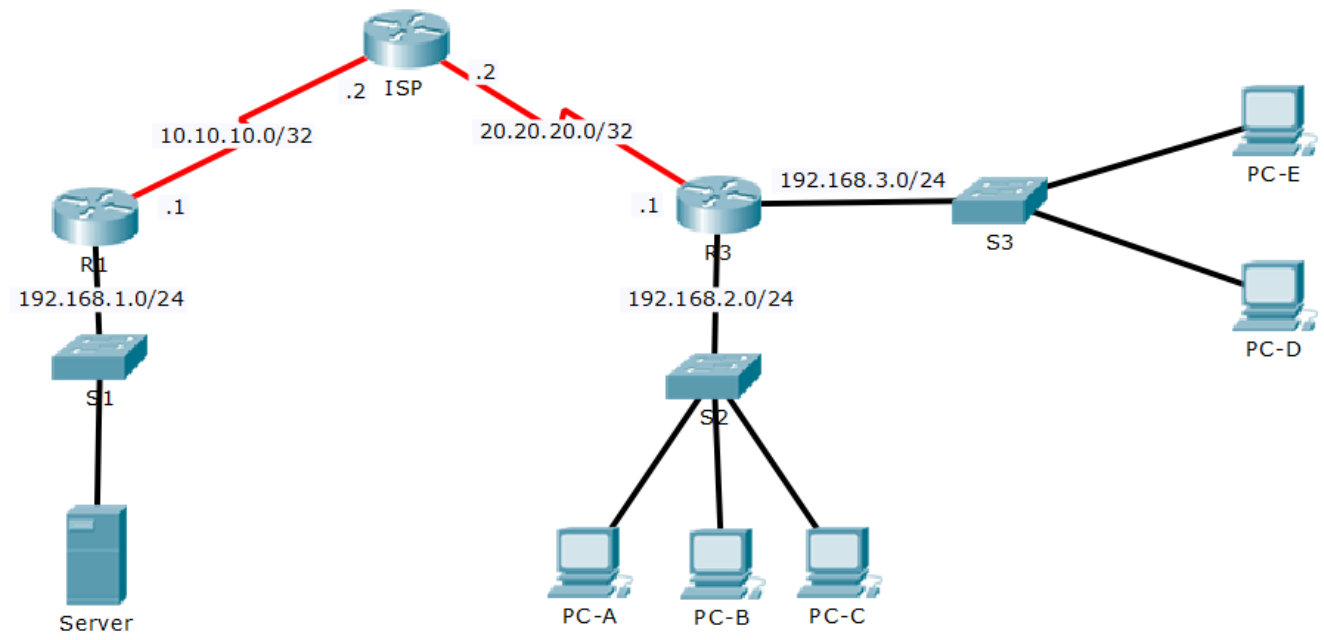

Gambar 2. Skema Jaringan

Skenario pengujian akan melakukan percobaan akses dari client dengan network 192.168.2.0/24 dan client dengan network 192.168.3.0/24 menuju ke server. Lalu, melakukan pengujian dari sisi server menuju ke network yang digunakan client serta melakukan uji konektifitas dari sisi client menuju client lainnya yang berada didalam network yang berbeda. 
Tabel 1. Spesifikasi IP Address

\begin{tabular}{cccc}
\hline Device & Interface & IPv4 & Gateway \\
\hline \multirow{2}{*}{ ISP } & Se0/0/0 & 10.10 .10 .2 & - \\
& $\mathrm{Se} 0 / 0 / 1$ & 20.20 .20 .2 & - \\
R1 & $\mathrm{Se} 0 / 0 / 0$ & 10.10 .10 .1 & - \\
& $\mathrm{G} 0 / 0$ & 192.168 .1 .1 & - \\
& $\mathrm{Se} 0 / 0 / 1$ & 20.20 .20 .1 & - \\
R3 & G0/0 & 192.168 .2 .1 & - \\
& G0/1 & 192.168 .3 .1 & - \\
Server & NIC & 192.168 .1 .2 & 192.168 .1 .1 \\
PC-A & NIC & 192.168 .2 .2 & \\
PC-B & NIC & 192.168 .2 .3 & 192.168 .2 .1 \\
PC-C & NIC & 192.168 .2 .4 & \\
PC-D & NIC & 192.168 .3 .2 & \\
PC-E & NIC & 192.168 .3 .3 & 192.168 .3 .1 \\
\hline
\end{tabular}

Dijelaskan pada Tabel 1 merupakan spesifikasi IP Address yang digunakan dalam pengimplementasian jaringan Zone-Base Policy Firewall. R1 menggunakan interface Se0/0/0 untuk terhubung dengan ISP dengan alokasi IP Address 10.10.10.1/24 dan interface G0/0 dengan alokasi IP Address 192.168.1.1/24 yang digunakan untuk menghubungkan jaringan lokal. Sedangkan, interface pada R3 yang terhubung dengan ISP adalah inteface Se0/0/1 dengan alokasi IP Address 20.20.20.1/24 dan interface G0/0 digunakan untuk jaringan lokal dengan alokasi IP Address 192.168.2.1/24 serta interface G0/1 dengan alokasi IP Address 192.168.3.1/24.

\subsection{Konfigurasi Static Routing}

Untuk mendukung pengimplementasian jaringan Zone-Base Policy Firewall sesuai dengan skema jaringan yang digunakan pada gambar 1. Penerapan static routing diperlukan untuk membentuk end to end antara IP Address yang menghubungkan router dengan router secara langsung. Konfigurasi static routing yang digunakan terhadap R1 adalah:

\section{Rl (config)\#ip route 0.0.0.0 0.0.0.0 10.10.10.2}

Pengimplementasian static route haruslah mempertimbangkan dan memperhatikan alokasi IP Address yang digunakan seperti yang tertera pada Tabel 1 serta memastikan alokasi IP Address tersebut sudah diimplementasikan didalam R1 maupun R3. R3 tidaklah luput dari konfigurasi static routing untuk mendukung suksesnya pengimplementasian jaringan Zone-Base Policy Firewall. Konfigurasi static routing yang digunakan terhadap R3 adalah:

$$
\text { R3(config)\# ip route 0.0.0.0 0.0.0.0 20.20.20.2 }
$$

Konfigurasi static routing haruslah memperhatikan IP Address dari Next-Hop atau Neighbour didalam jaringan yang digunakan.

\subsection{Uji Konektifitas Jaringan Sebelum Penerapan Zone-Base Policy Firewall}

Sebelum diimplementasikannya keamanan jaringan menggunakan metode Zone-Base Policy Firewall, semua client yang terkoneksi didalam jaringan dapat berkomunikasi dengan server tanpa adanya batasan akses diantara server dengan client. Dijelaskan pada gambar 3 merupakan hasil traceroute dari client dengan network 192.168.2.0 menuju ke server dengan memiliki 4 hop-count dengan melalui gateway 192.168.2.1 menuju 20.20.20.2 menuju ke 10.10.10 hingga sampai pada server. 


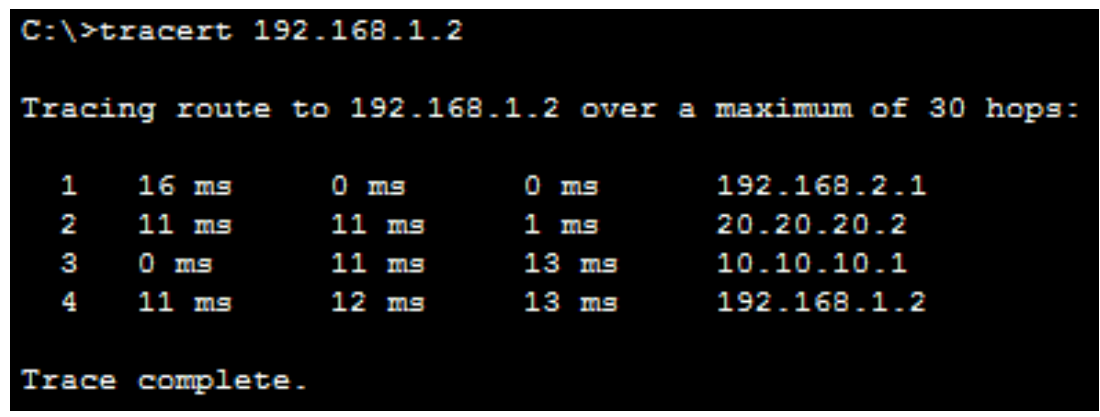

Gambar 3. Tracer 192.168.2.0 menuju Server

Sedangkan dijelaskan pada gambar 4, merupakan uji konektifitas dari client dengan network 192.168.3.0 menuju ke server. Terlihat hop-count yang pertama dilalui oleh client adalah gateway dengan alokasi IP Address 192.168.3.1 lalu menuju 20.20.20.2 menuju ke 10.10.10 hingga sampai pada server, serta lalu lintas tranfer paket data dari client menuju ke server dapat berjalan dengan baik.

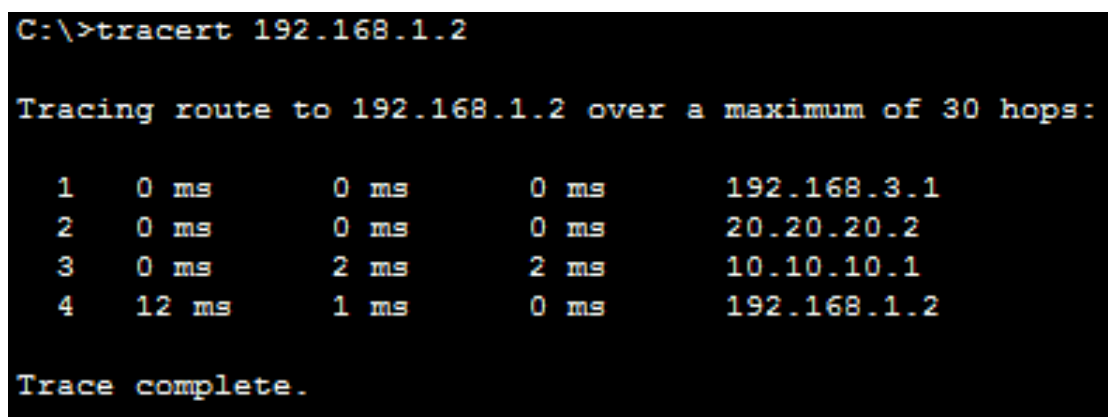

Gambar 4. Tracer 192.168.3.0 menuju Server

\subsection{Konfigurasi Zone-Base Policy Firewall}

Security Technology package sangatlah berperan penting dalam pengimplementasian Zone-Base Policy Firewall dikarenakan jika tidak mengaktifkan technology-package akan berdampak tidak dapat diimplementasikannya Zone-Base Policy Firewall. Terlihat pada gambar 5 sebelum pengaktifan Technology-package pada Cisco IOS.

\begin{tabular}{lccc} 
Technology Package License Information for Module: 'c1900' & & \\
\hline & & & \\
Technology & Technology-package & Technology-package \\
& Current & Type & Next reboot \\
ipbase & ipbasek9 & Permanent & ipbasek9 \\
security & disable & None & None \\
data & disable & None & None
\end{tabular}

Gambar 5. Sebelum Pengaktifan Technology-package

Untuk mengaktifkan Technology-package pada Cisco IOS dapat menggunakan konfigurasi:

\section{R3(config)\#license boot module c1900 technology-package securityk9}

Konfigurasi tersebut dapat digunakan untuk mengaktifkan Technology-package dan hasil dari pengaktifan Technologypackage terlihat pada gambar 6 . 


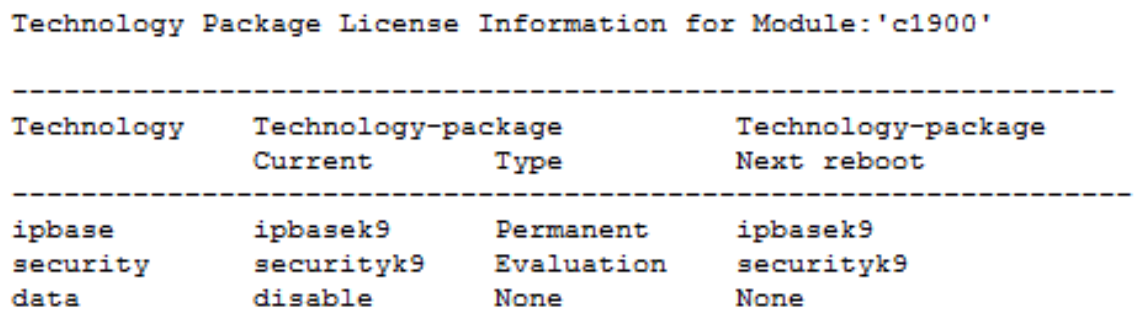

Gambar 6. Setelah Pengaktifan Technology-package

Setelah mengaktifkan fitur securityk9 langkah selanjutnya mengaktifkan zona yang akan digunakan, baik zona internal maupun zona external serta pengimplementasian access control list pada R3. Konfigurasi pengaktifan zona dan Access Control List (ACL) hanya dilakukan pada R3 dengan menggunakan perintah:

\author{
R3(config)\#zone security Z-INSIDE \\ R3(config)\#zone security Z-OUTSIDE \\ R3(config)\#access-list 101 permit ip 192.168.3.0 0.0.0.255 any \\ R3(config)\#class-map type inspect match-all INSIDE-PROTOCOL \\ R3(config-cmap)\#match access-group 101
}

Pembatasan akses menggunakan access-list bermaksud untuk membatasi akses hanya dapat dilalui dan diizinkan oleh network 192.168.3.0/24 saja. Metode yang digunakan dalam pengimplementasian Zone-Base Policy Firewall menggunakan Inspect untuk mengamanakan secara privasi antara Source Member Zone dengan Destination Member Zone. Maka akses dari alamat selain Member Zone tersebut akan terblok aksesnya. Untuk pengimplementasian Zone-Base Policy Firewall penggunaan ACL tidaklah sebatas permit dan deny. Namun, menggunakan firewall policy yang lebih spesifik untuk menentukan matched terhadap traffic yang akan diamankan.

\title{
R3(config)\#policy-map type inspect INSIDE-TO-OUTSIDE R3(config-pmap)\#class type inspect INSIDE-PROTOCOL R3(config-pmap-c)\#inspect
}

\section{R3(config)\#zone-pair security INSIDE-TO-OUTSIDE-Z source Z-INSIDE destination Z-OUTSIDE R3(config-sec-zone-pair)\#service-policy type inspect INSIDE-TO-OUTSIDE}

\subsection{Uji Konektifitas Jaringan Dengan Zone-Base Policy Firewall-1}

Uji konektifitas yang pertama kali dilakukan adalah memastikan fungsional dari pengimplementasian zona inside yang digunakan pada jaringan lokal R3. Pengujian kinerja jaringan dapat dilakukan dengan cara melakukan pengiriman paket ICMP dari jaringan local client menuju Server. Terlihat pada gambar 7 merupakan hasil pengujian konektifitas paket ICMP dari client yang menggunakan network 192.168.3.0 berstatus sukses yang artinya jaringan dapat berjalan dengan baik.

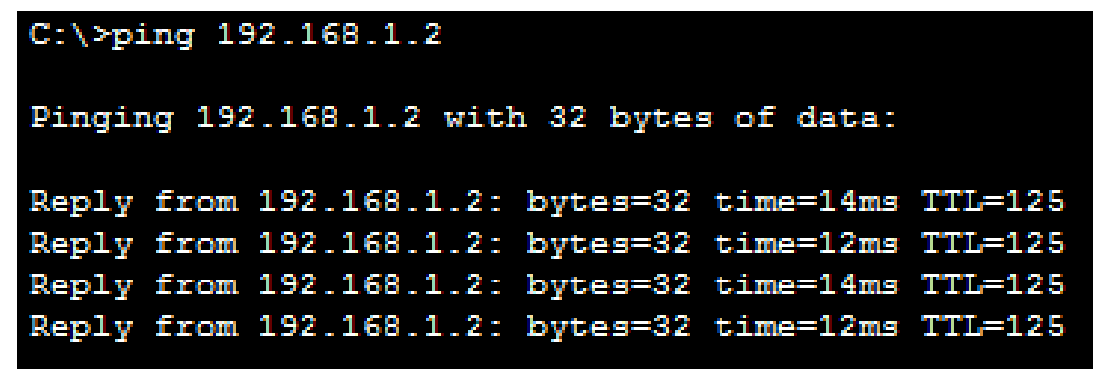

Gambar 7. Pengujian ICMP dari Network 192.168.3.0

Sedangkan, pengujian yang dilakukan dari sisi client dengan network 192.168.2.0 menuju ke server berstatus Request timed out, terlihat pada gambar 8. Hal ini terjadi dikarenakan telah diimplementasikannya Zone-Base Policy Firewall yang mampu melakukan pembatasan akses client menuju ke server hanya dapat dilalui oleh network 192.168.3.0 


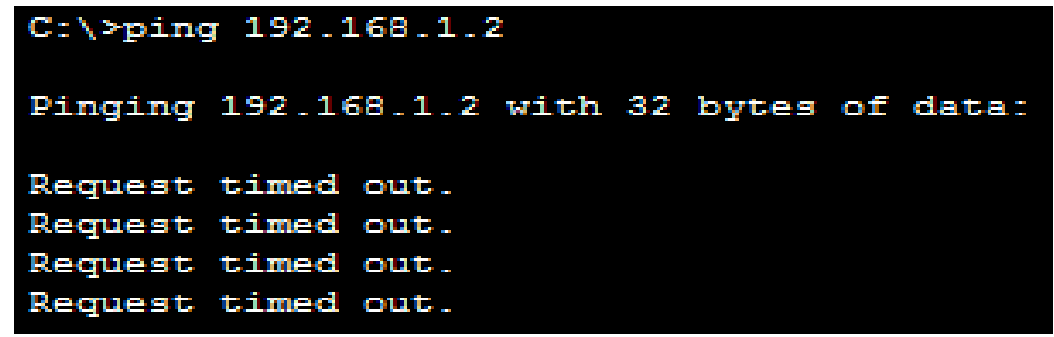

Gambar 8. Pengujian ICMP dari Network 192.168.2.0

Dijelaskan pada gambar 9 merupakan policy map yang didapatkan pada R3. Policy map akan memberikan informasi log traffic didalam lalu lintas router dengan memberikan note Service-policy inspect: INSIDE-TO-OUTSIDE sesuai dengan pengimplementasian. Terlihat session 390434776 dengan IP Address 192.168.3.3:50 melakukan akses menuju 192.168.1.2:0 dengan menggunakan paket ICMP dan dengan status pengiriman paket ICMP dari client Drop.

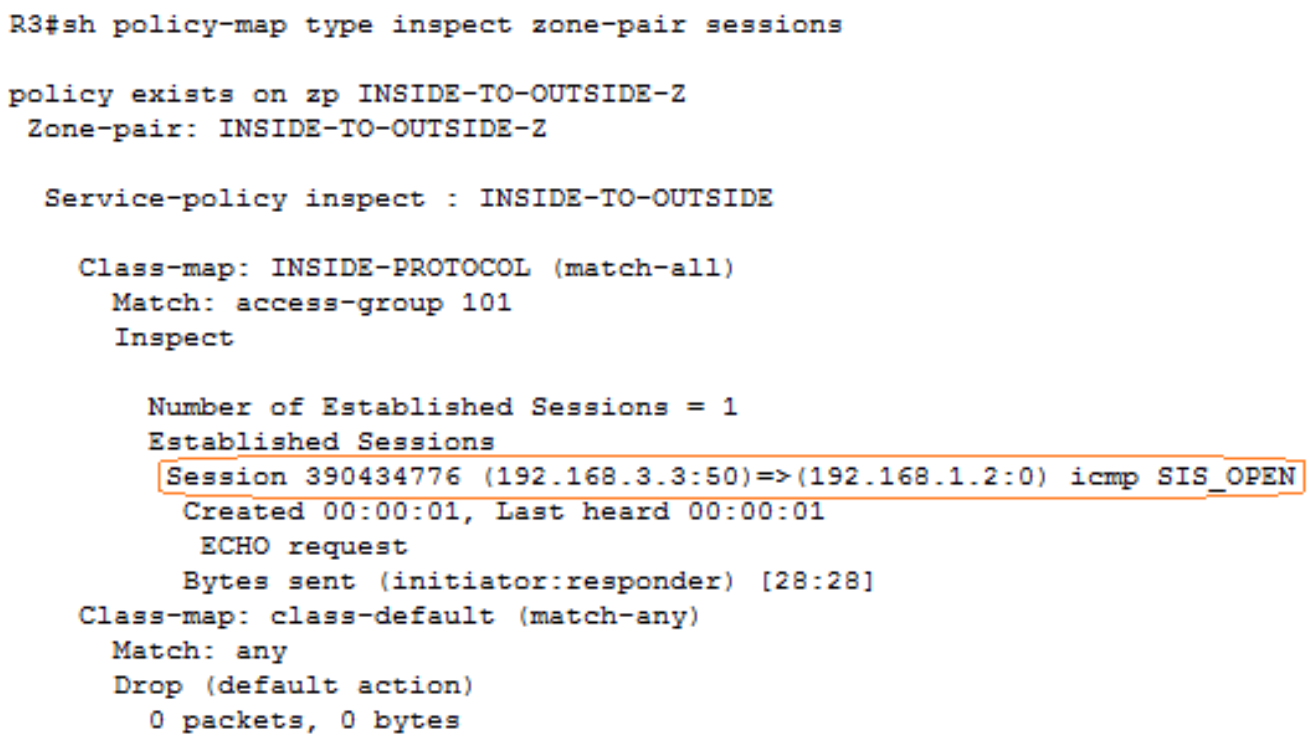

Gambar 9. Policy Map ICMP

\subsection{Uji Konektifitas Jaringan Dengan Zone-Base Policy Firewall-2}

Pengujian yang kedua adalah melakukan uji konektifitas terhadap akses HTTP menuju server dari sisi client yang menggunakan network 192.168.3.0. Terlihat pada gambar 10 merupakan hasil policy map yang didapatkan ketika terdapat zona yang sama melakukan akses menuju ke server.

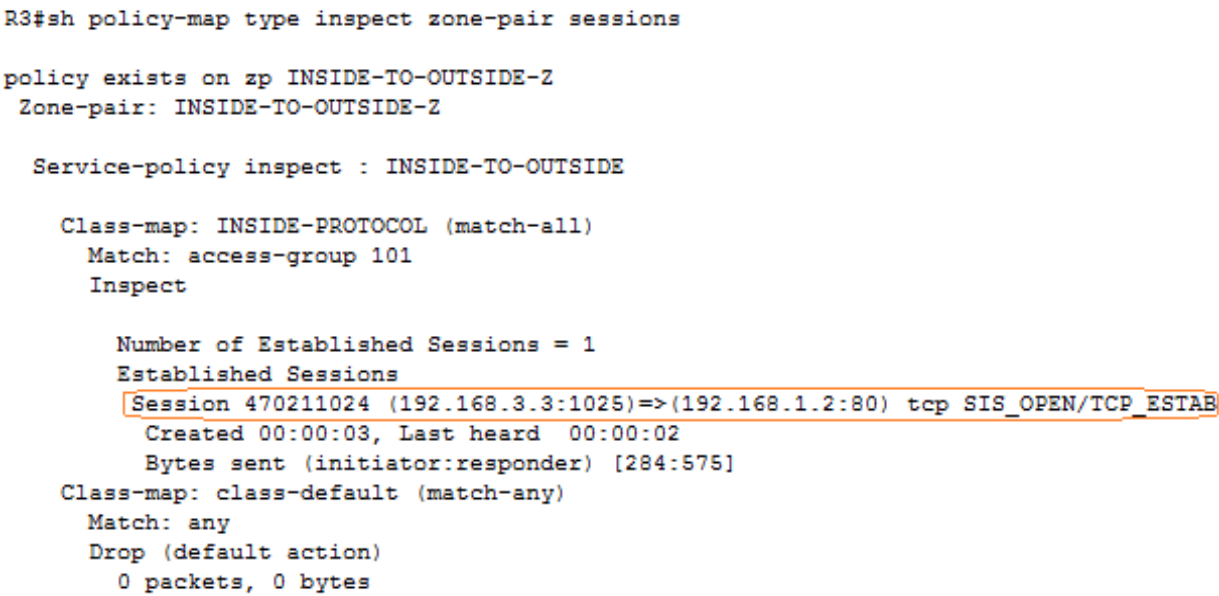

Gambar 10. Policy Map HTTP 


\subsection{Uji Konektifitas Jaringan Dengan Zone-Base Policy Firewall-3}

Pengujian yang ketiga pada jaringan Zone-Base Policy Firewall adalah melakukan uji konektifitas secara menyeluruh seperti yang terlihat pada tabel 2 .

Tabel 2. Uji Konektifitas Jaringan Zone-Base Policy Firewall

\begin{tabular}{llll}
\hline \multicolumn{1}{c}{ Source } & \multicolumn{1}{c}{ Destination } & \multicolumn{1}{c}{ Protocol } & \multicolumn{1}{c}{ Status } \\
\hline 192.168 .2 .0 & 192.168 .3 .0 & ICMP & Success \\
\hline 192.168 .2 .0 & Server & ICMP & Request Timed Out \\
\hline 192.168 .2 .0 & Server & HTTP & Request Timed Out \\
\hline 192.168 .3 .0 & 192.168 .2 .0 & ICMP & Success \\
\hline 192.168 .3 .0 & Server & ICMP & Success \\
\hline 192.168 .3 .0 & Server & HTTP & Success \\
\hline Server & 192.168 .2 .0 & ICMP & Request Timed Out \\
\hline Server & 192.168 .3 .0 & ICMP & Request Timed Out \\
\hline
\end{tabular}

Tabel 2 menjelaskan bahwa client dengan network 192.168.2.0 hanya dapat melakukan konektifitas terhadap client dengan network 192.168.3.0 dan tidak dapat melakukan akses terhadap server baik menggunakan protokol ICMP maupun HTTP. Sedangkan client dengan network 192.168.3.0 mampu melakukan akses terhadap keseluruhan jaringan berjalan baik untuk berkomunikasi antara client maupun berkomunikasi dengan server. Dan dari sisi server tidak dapat melakukan komunikasi menuju client dengan network 192.168.2.0 dan client dengan network 192.168.3.0.

\subsection{Uji Konektifitas Jaringan Dengan Zone-Base Policy Firewall-4}

Keamanan jaringan komputer menggunakan metode Zone-Base Policy Firewall mampu menyembunyikan hop count yang dilalui, terlihat pada gambar 11. Tracert yang dilalui dari client dengan network 192.168.3.0 menuju ke server hanya menampilkan alokasi gateway dari source dan destination tanpa memberikan informasi dari hop count yang dilaluinya.

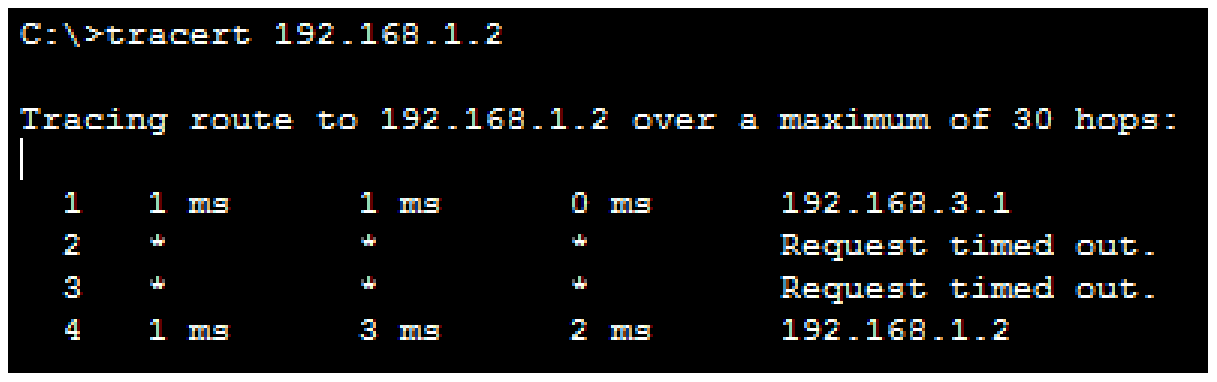

Gambar 11. Tracert Network 192.168.3.0

\section{KESIMPULAN}

Penerapan keamanan jaringan menggunakan metode Zone-Base Policy Firewall mampu meminimalisir terjadinya kebocoran data yang bersifat pribadi dan sangat rahasia. Dikarenakan sistem keamanan yang digunakan pada Zone-Base Policy Firewall melakukan pembatasan akses berdasarkan zona yang sama dengan melakukan pertimbangan nama zona dan manajemen zona yang digunakan. Ketika terdapat pengguna yang mencoba melakukan akses kedalam jaringan yang diamankan maka akses tidak akan diizinkan dikarenakan. Pengimplementasian Zone-Base Policy Firewall mampu menyingkat penggunaan access control list serta lebih mempermudah dalam melakukan maintenance didalam jaringan. Dari hasil penelitian didapatkan server hanya dapat diakses dari client dengan zona yang sama atau client dengan network 192.168.3.0. Serta Zone-based policy firewall mampu menyamarkan hop count didalam jaringan guna meningkatkan keamanan lalu lintas transfer paket data.

\section{REFERENSI}

[1] F. Firmansyah, M. Wahyudi, and R. A. Purnama, "Analisis Performa Site to Site IP Security Virtual Private Network (VPN) Menggunakan Algoritma Enkripsi ISAKMP,” JUITA Jurnal Informatika, vol. 7, no. 2, pp. 129-135, 2019.

[2] B. Sugiantoro, “Analisa Usabilitas Sistem Deteksi Akses Pornografi Pengguna Internet Menggunakan Metode Mccall’S,” JOIN Jurnal Online Informatika, vol. 2, no. 1, pp. 56-61, 2017. 
[3] M. Irfan, M. A. Ramdhani, W. Darmalaksana, A. Wahana, and R. G. Utomo, "Analyzes of cybercrime expansion in Indonesia and preventive actions,” IOP Conference Series Matererials Science and Engineering, vol. 434, no. 1, pp. 1-7, 2018.

[4] I. Anugrah and R. H. Rahmanto, "Sistem Keamanan Jaringan Local Area Network Menggunakan Teknik De-Militarized Zone," PIKSEL Peneliti Ilmu Komputer Sistem Embedded \& Logic, vol. 5, no. 2, pp. 91-106, 2018.

[5] M. Yusup, Maisyaroh, and L. Septiana, "Securing Web Application by Embedded Firewall at Gytech Indosantara Mandiri Ltd.," PIKSEL Peneliti Ilmu Komputer Sistem Embedded \& Logic, vol. 8, no. 1, pp. 49-58, 2020.

[6] B. Fachri and F. H. Harahap, "Simulasi Penggunaan Intrusion Detection System (IDS) Sebagai Keamanan Jaringan dan Komputer," Jurnak Media Informatika Budidarma, vol. 4, no. 2, pp. 413-420, 2020.

[7] C. E. Suharyanto, “Analisis Penggunaan Access Control List (Acl) Dalam Jaringan Komputer Di Kawasan Batamindo Industrial Park Batam,” Jurnal Informatin System Development, vol. 2, no. 2, pp. 122-128, 2019.

[8] R. Novrianda, "Simulasi Teknologi Frame Relay Pada Jaringan Vpn Menggunakan Cisco Packet Tracer the Simulation of Frame Relay Methods on Vpn Networks Using Cisco Packet Tracer," Jurnal Digital, vol. 1, no. 1, pp. 45-55, 2018.

[9] H. Supendar and Y. Handrianto, "Teknik Frame Relay Dalam Membangun Wide Area Network Dengan Metode Network Development Life Cycle,” Bina Insani. ICT Journal, vol. 4, no. 2, pp. 121-130, 2017.

[10] S. Arlis, “Analisis Firewall Demilitarized Zone Dan Switch Port Security Pada Jaringan,” Jurnal KomtekInfo ( Komput. Teknol. Inf. ), vol. 6, no. 1, pp. 29-39, 2019.

[11] B. M. Sukhovilov and E. A. Grigorova, "Development of System for Protecting IT Environment of Enterprise Based on Demilitarized Zone Concept Using Virtualization Technology," in Proceedings - 2018 Global Smart Industry Conference, GloSIC 2018, 2018, pp. 16.

[12] K. Demertzis and L. Iliadis, "Cognitive Web Application Firewall to Critical Infrastructures Protection from Phishing Attacks," Journal of Computations \& Modelling, vol. 9, no. 2, pp. 1792-8850, 2019.

[13] R. Vanickis, P. Jacob, S. Dehghanzadeh, and B. Lee, “Access Control Policy Enforcement for Zero-Trust-Networking,” 29th Irish Signals Systems Conference ISSC 2018, vol. 1, no. 2, pp. 1-6, 2018.

[14] K. Kurniati and R. N. Dasmen, "The Simulation of Access Control List (ACLs) Network Security for Frame Relay Network at PT. KAI Palembang," Lontar Komputer Jurnal Ilmiah Teknologi Informasi, vol. 10, no. 1, pp. 49-61, 2019.

[15] Firmansyah, S. Dewi, and R. adi Purnama, "Quality Of Service Gateway Load Balancing Protocol Message Digest Algorithm 5 Authentication Untuk Peningkatan Kualitas Jaringan,” Jurnal Teknik Informatika, vol. 5, no. November, pp. 45-50, 2020. 
Matrik : Jurnal Manajemen, Teknik Informatika, dan Rekayasa Komputer, Vol. 20, No. 2, Mei 2021: 283 292 